\section{Movilizando saberes ciudadanos: encontrar un lugar, construir la verdad}

Mobilizing Citizen Knowledge: finding a place, building truth

\section{Consuelo Biskupovic EduARdo Canteros ${ }^{* * *}$}

\section{Resumen}

Basándonos en los resultados de nuestras tesis doctorales, las que abordaron el trabajo político de agrupaciones movilizadas para defender barrios y medio ambiente en Santiago de Chile, este artículo se centra en el "saber ciudadano". Comprendemos el saber ciudadano como una creación colectiva reivindicativa de legitimidad frente a diferentes públicos. Darle un lugar

* Las tesis que sirven de base para este artículo contaron con el apoyo de becas CONICYT y los apoyos financieros de la Facultad de Arquitectura y Estudios Urbanos de la Pontificia Universidad Católica de Chile y para terreno de Ecole des Hautes Etudes en Sciences Sociales, París.

** Universidad Academia de Humanismo Cristiano, Av. Condell 343, Providencia, Santiago.mbiskupovic@academia.cl

*** Departamento de Trabajo Social. Universidad Alberto Hurtado, Erasmo Escala 1884, tercer piso, Santiago. ecantero@uahurtado.cl propio a este saber permite, en los estudios de la acción colectiva y de la participación, dar cuenta de descripciones y de diferentes registros de conocimiento respecto a la ciudadanía, los que entran en interacción, negociación y conflicto. Este artículo busca situar el saber ciudadano más allá de la díada saber experto/saber profano, dando cuenta de la capacidad política, reflexiva y creativa de los ciudadanos para comprender y gestionar sus territorios. Para ello, analizamos el saber ciudadano a partir de tres dimensiones: como forma política, en tanto que comunidad política donde se discute y construye el territorio y, por último, como posibilidad para los ciudadanos de tener reconocimiento y legitimidad en la democracia.

Palabras clave: Saber ciudadano, experticia, democracia, territorio, Santiago.

\begin{abstract}
This article focuses on "citizen knowledge" as a collective creation that claims political legitimacy inside of territorial public policy debate. With this idea, we seek to go beyond the dichotomy between expert and profane knowledge. Based on the results of two doctoral researches, we analyze the political work of mobilized groups who attempt to defend neighborhoods and environment in Santiago de Chile. We focused on how the associations enter to interaction, negotiation and conflict, and how they mobilize and create knowledge for having space in a public policy discussion, traditionally closed to citizens. We analyze the citizen knowledge from three dimensions: as a political form, as a way for building and
\end{abstract}


discussing the territory, and as a possibility for citizens to have recognition and legitimacy in democracy.

Key words: Citizen knowledge, expertise, democracy, territory, Santiago.

\section{Introducción}

Este artículo aborda el saber ciudadano entendido como aquel producido y movilizado para gestionar, controlar y crear el mundo que nos rodea. Este saber construye discursos, reglas, posiciones e impulsa la búsqueda de una verdad que intenta, frente a diferentes públicos, demostrar su efectividad en la "gestión" del territorio.

Generalmente el saber ciudadano se ha concebido desde la idea de "conocimiento local", el que es asociado a una comprensión "no moderna" (Escobar 1997 citado por Mignolo 2003: 381) del entorno, como parte de lo que Escobar llama la "naturaleza orgánica", y que se distingue de la "naturaleza capitalizada" y la "tecnonaturaleza" (ibid.).

No pretendemos introducir una tipología ni dar cuenta de unalista exhaustivasobre los diferentes conocimientos ciudadanos. El conocimiento ciudadano se vincula con diferentes y multiples dimensiones como la ciencia, el territorio, el desarrollo urbano, entre muchas otras. Este trabajo busca más bien extender la noción de saber ciudadano, ampliándola a los saberes que detentan los habitantes de un lugar, permitiéndonos repensar el saber y el rol que le corresponde a los ciudadanos en la democracia (Callon et al. 2001).
Si bien el rol de los ciudadanos en los procesos institucionales, como la participación ciudadana promovida por el Estado, puede estar normado o limitado, como ocurre en el caso de los procedimientos que contemplan la ley (por ejemplo, la Ley Sobre Bases Generales del Medio Ambiente $\mathrm{N}^{\circ} 19.300$ ), éste se transforma en un procedimiento indeterminado, un proceso de disputa por participar, por definir ese rol. La sola puesta en marcha de dispositivos de participación o que busquen enmarcar el saber ciudadano no asegura una participación representativa y exitosa para los ciudadanos (Berger 2014). Pero tal como veremos en este artículo, el saber ciudadano, los procedimientos y encuadres que realizan las personas, en algunos casos les aseguran una legitimidad a la hora de interactuar con autoridades, profesionales, otros vecinos (Ollitrault y Jouzel 2015) pero en otros el saber les sirve a los ciudadanos para poder asegurar un cupo en las interacciones y espacios donde se toman las decisiones.

Algunos autores señalan que uno de los mayores problemas que enfrentan los ciudadanos al intentar participar de los asuntos y modificaciones en los territorios en los que viven, viene del lenguaje extremadamente técnico de estos procesos, volviendo casi inaccesible para un ciudadano el procedimiento normativo (Tironi et al. 2011: 277). Sin embargo, y como este lenguaje exige precisión, tal como lo sugiere Heloïse Nez (2011), los ciudadanos, organizándose, creando asociaciones ciudadanas para participar en la vida pública, reuniéndose con diferentes actores, desarrollan saberes y prácticas respecto a los territorios y son capaces de familiarizarse con, o desarrollar un lenguaje, que les permite, además de dialogar con otros actores, crear o explicitar un saber propio respecto a lo que los rodea. 
Por su parte, las autoridades tienen también dificultades para integrar el saber y las capacidades de los ciudadanos y usuarios (Biskupovic 2015). Las políticas públicas suelen pensarse desde un saber técnico que limita a priori el saber y la acción de la ciudadanía, desde la experticia de técnicos y expertos, no desde los usuarios (Ureta 2017). Este autor plantea que las políticas públicas hacen frente, mal o bien, a "dispositivos humanos", los que tienen una importancia trascendental "en los ensamblajes de políticas públicas" (p. 223). Como apunta Ureta, al considerar una política pública como un ensamblaje, esta debiera asumir, al mismo tiempo, un aumento de conflictos y tensiones entre las diferentes entidades.

El aumento de la conflictividad ${ }^{1}$ en Santiago (Garretón et al. 2017) o de los procedimientos dondelos habitantessonincorporadosen políticas públicas que los impactan, crea un escenario que tensiona la ciudadanía contemporánea. En este artículo pensamos la ciudadanía como una cuestión performativa en el sentido que, en primer lugar, los ciudadanos deben resolver o hacer frente a una situación política (soberanía) y a una cuestión social (gobierno de las diferencias materiales) (Landau 2008). Y, en segundo lugar, al ser un ejercicio crítico de denuncia y propuesta, la ciudadanía va transformando su significado y funciones (Isin 2017).

En este marco, los dos casos que estudiamos, "Vecinos por la Defensa del Barrio Yungay" $(\text { VDBY })^{2}$ y la "Red de Defensa de la Precordillera"

\footnotetext{
La definición y estudio de conflicto social no es el objetivo de este artículo, por ende, nos limitamos a señalar que las demandas de organizaciones y movimientos sociales para proteger y defender sitios en el país son cada vez mayores.

2 La agrupación "Vecinos por la defensa del Barrio Yungay" (VDBY), nació el año 2005 a partir de un grupo de habitantes del barrio que se organizaron para oponerse al cambio del régimen del retiro de
}

$(\mathrm{RDP})^{3}$ representan la lucha de los ciudadanos para que sus experiencias, saberes y usos de los espacios en el que viven sean incluidos en las políticas públicas relativas a sus barrios.

Este artículo busca reformular la idea de saber ciudadano, alejándose de aquellas concepciones que lo vinculan con una visión "no moderna" del conocimiento que tienen las personas respecto al lugar que habitan. Para esto, las investigaciones que aquí presentamos contemplan los procesos en los cuales la ciudadanía participa como entramados híbridos (Callon et al. 2001; Callon 2004; Lolive 2006; Blok y Jensen 2011). Por ende, no buscamos estudiar por un lado los expertos y por el otro a los profanos o a los no-expertos, o por una parte al conocimiento moderno y por otra al pre-moderno o "natural". Sino que más bien

la basura impulsado desde la administración municipal. Desde esa fecha hasta el día de hoy, tras trece años de trabajo ininterrumpido, han emprendido una gran cantidad de iniciativas entre las que se cuentan la publicación de la revista Bello Barrio, festivales anuales del Roto Chileno, fiesta de la primavera, talleres literarios, entre otras actividades. Al alero de esta agrupación se han creado otras organizaciones tales como el Club deportivo el Gran Yungay, Junta de Vecinos Barrio Yungay, Comité de Vivienda, entre otros, así como centros de formación (Escuela Taller de artes y oficios Fermín Vivaceta). Como uno de sus grandes logros, en febrero del año 2009 obtuvieron, para 116 de las hectáreas el barrio, la declaración de zona típica por parte del Consejo de Monumentos Nacionales, a la cual, el 24 de enero de 2018, lograron sumar otras 80 hectáreas, convirtiéndose en la zona típica urbana más grande de Chile.

3 Frente al creciente desarrollo inmobiliario en la precordillera de la comuna de la Florida de Santiago de Chile, un grupo de vecinos comienza a organizarse en 1995, sobre todo después del desastre y las muertes provocadas por el aluvión en Lo Cañas en 1993. Este colectivo pasa a llamarse Red de defensa de la precordillera (RDP) cuando es inscrita como asociación ciudadana en el 2006 en dicha comuna por un grupo de aproximadamente ocho personas. Este colectivo, diez años después, logra movilizar a un gran número de personas en La Florida y en el 2012, uno de sus grandes éxitos, se aprueba un plebiscito comunal para convertir un parque privado, conocido como "El Panul", en parque comunal. Este terreno, que los vecinos de esta agrupación han venido protegiendo, defendiendo y estudiando por más de diez años, alberga un bosque esclerófilo con vegetación nativa de gran importancia para la cuenca de Santiago. El propietario, sin embargo, prevé hace varios años un proyecto inmobiliario en este lugar, al que los vecinos se oponen. 
describiremos diferentes formas de creación de saber por parte de los ciudadanos. El objetivo es entender cómo los ciudadanos crean saberes ciudadanos. Para ello, en una primera instancia definimos formas que toma el saber ciudadano, luego abordamos el rol que el saber que desarrollan los ciudadanos puede otorgarles. En una tercera etapa, proponemos tres dimensiones a partir de las cuáles es posible estudiar y comprender el rol del saber ciudadano.

\section{Formas del saber ciudadano}

La intervención y el papel de los expertos en la esfera pública ha sido ampliamente estudiada los últimos veinte años (Barbier et al. 2013). Por su parte, el papel del saber ciudadano, tal como señala Sintomer, ha sido utilizado de manera difusa y grandilocuente (2008: 115).

La sociología de la controversia ha permitido relativizar la "irracionalidad ignorante" con que comúnmente se pensaba el rol de los notécnicos o no-científicos (Estades y Remy 2003). Esta "ha acordado de manera simétrica igual importancia a las competencias y a los argumentos movilizados por todos los actores concernidos por una situación incierta o controversial" (Estades y Remy 2003: 15). Esta igual importancia acordada en la academia está lejos de encontrar simetría entre las políticas públicas y en los espacios donde pueden participar los ciudadanos.

Sin embargo, las organizaciones ciudadanas se posicionan cada vez más en la arena pública en tanto que afectados (directamente concernidos por un problema), solicitando poder incidir en la toma de decisión. En esta línea, John Dewey señalaba en su clásico The Public and Its Problems de 1927 que es "la persona que lleva el zapato puesto es quién mejor sabe si le duele y dónde" (citado por Sintomer 2008: 115). La proximidad y uso regular están en el corazón de esta idea defendida por Dewey, quien considera que los expertos técnicos están alejados del interés común (ibid.).

El concepto de saber ciudadano hace referencia a un conocimiento disponible y existente para todos (Sintomer 2008: 116). Según este autor, dentro de este marco es posible distinguir dos variantes: i) el "saber de uso", según la cual forjamos nuestras ideas en tanto usuarios o afectados; ii) el "buen juicio", es decir, cuando a los ciudadanos se los convoca a participar apelando a su justo criterio, a que sean capaces de juzgar sin pasiones (Sintomer 2008).

El saber de uso es un saber que es forjado por el hecho de ser usuarios (de un parque, de un barrio, de un dispositivo, de un transporte, etc.). Por su parte, el buen juicio, o el buen sentido, necesita información suficiente para poder desarrollar una opinión clara y concienzuda. Esta última variante amplía el espectro de participantes en la democracia pues subentiende que todos pueden tener buen juicio y que el saber está disponible para todos.

Además de estos saberes, Sintomer distingue otros como el saber ciudadano experto, que hace referencia a un saber técnico. $Y$ el saber por delegación, en que el Estado delega, por ejemplo, a asociaciones, ciertos conocimientos técnicos.

Sintomer distingue además el saber ciudadano bajo la forma de "contra-experticia", es decir, aquel saber movilizado por ciudadanos en 
controversias técnicas o científicas que buscan contrarrestar o abrir el debate creando un saber alternativo al de los expertos que crean las políticas. Les permite a los ciudadanos en cierto sentido volverse "actores legítimos" en la "democracia técnica" (Sintomer 2008: 125). Este saber, común entre los movimientos sociales, solicita a los poderes públicos espacios y medios para poder incidir y mostrar su contraexperticia (Sintomer 2008).

Considerando lo que dice Sintomer, podemos pensar que el saber ciudadano, o la experticia ciudadana, corresponde a un conjunto de formas y de procesos a través de los cuales los ciudadanos pueden participar de la esfera pública. En este proceso, los actores que estudiamos, adquieren diferentes saberes que combinan y suman: saber por uso y experiencia, adquieren experticia, capacidad para asumir la delegación y la gestión de sitios, y la contraexperticia para discutir informes, documentos y conocimiento profesional.

El proceso hacia la experticia es también un proceso de exploración (Barthe 2003), en este sentido, no podemos obviar el hecho que grupos ciudadanos atraviesen y obtengan éxitos en esta exploración es arduo. Aquellos que pueden desarrollar un saber político y profesional son los que tienen recursos tanto materiales como inmateriales, capital social y cultural, así como tiempo disponible, perseverancia, trayectoria, capacidad colectiva, entre otros. Estos, sin duda, no son sino una minoría de ciudadanos (Sintomer 2008). En los grupos que aquí estudiamos, los recursos inmateriales son los que han hecho que consoliden sus saberes. La capacidad de aprehender las oportunidades donde desplegar los saberes es posiblemente el recurso que estos grupos más han sabido valorar.
La particularidad es que, si bien, cuentan con escasos recursos materiales (logrados gracias a rifas, bingos u otro tipo de actividades), estos grupos están liderados por profesionales que logran legitimidad gracias a la contra-experticia y a gestiones administrativamente efectivas - tal como veremos hacia el final del artículo - que construyen, difunden y muestran internamente como públicamente.

\section{El saber ciudadano en el contexto democrático chileno.}

La producción de conocimiento por los afectados no es algo nuevo ${ }^{4}$, más bien ha emergido como una opción crítica en los debates de controversias sanitarias y ambientales, frente a los saberes institucionales sobre los que se fundan las políticas públicas (Ollitrault y Jouzel 2015: 87). El saber técnico no lo detentan sólo los que ocupan funciones oficiales, sino que también los "ciudadanos 'simples" (Sintomer 2008).

Los estudios de la ciencia y la sociología de la controversia han demostrado que las decisiones ya no pueden ser sólo técnicas, pues comprometen voluntades diversas que pueden ser "culturales, sociales o políticas" (Sintomer 2008: 132).

Los procedimientos que llevan a cabo las agrupaciones estudiadas, tal como reuniones con funcionarios y profesionales, diálogos, - debates, son verdaderas escuelas para la democracia (Biskupovic 2015). En este contexto en que se intercambian saberes y

Ver en el caso chileno por ejemplo el rol que jugaron los "observadores de terremotos" en la sistematización sísmica a inicios del s. XX (Valderrama, 2014). 
categorías técnicas, definiciones y reglamentos, la experticia técnica y científica es inseparable de un saber político (ibid.). En el Chile actual, las organizaciones que hemos estudiado traducen y construyen saberes en base a un proyecto político que tiene por objetivo la protección del territorio. Estudiar la acción colectiva de estas organizaciones en tanto que escuelas para la democracia permite resituar el rol de los ciudadanos frente a una estructura que autoriza rara o casi nulamente una participación vinculante.

En estas escuelas para la democracia en que participan las organizaciones como la RDP y VDBY, los ciudadanos aprenden y comprenden el funcionamiento del Estado (Sintomer 2008), los marcos legales, opinan respecto a las controversias, se forman y se movilizan. En un contexto como el chileno - en que los ciudadanos participan la mayoría de las veces "autoconvocadamente", más que a través de dispositivos y procesos deliberativos organizados por instituciones públicas o privadas - las escuelas de la democracia y la cultura cívica "tienen una función de legitimación" (ibid: 129) para los ciudadanos.

En el barrio Yungay y Lo Cañas los habitantes tienen saberes profesionales y sus capacidades de intervención y de compromiso son superiores a otros casos de marginalidad y de pobreza urbana (Auyero 2004). Entre los principales factores que explican esta diferencia es que, tanto en Yungay como en Lo Cañas, los saberes han sido consolidados por clases medias con acceso a información y saberes que les permiten construir una contra-experticia. Los grupos estudiados aquí son de clase media con alto capital técnico profesional y de gestión, que han buscado influir en sus territorios vía el saber. El acceso a este lo han obtenido básicamente por dos vías: gracias al capital con el que pueden desclasificar, descargar, encontrar, conseguir, analizar y proponer frente a información científica e informes técnicos sobre sus barrios (flora, fauna, territorio, planificación urbana, geografía, etc.). La segunda vía, gracias a las redes que tienen, los ciudadanos pueden lograr reuniones, encuentros, entrevistas con profesionales (arquitectos, abogados, geógrafos, biólogos, físicos, autoridades, etc.) para obtener nuevos saberes que ellos mismos producen basándose en el material de los profesionales.

Cabe señalar que los grupos aquí estudiados pertenecen a clases medias intelectuales participantes del desarrollo al cual alude Sintomer. Tal como argumenta este autor, con la formación de las clases medias intelectuales y el desarrollo de la sociedad del conocimiento, el nivel de educación es cada vez más elevado en los movimientos sociales, así como también el capital cultural y técnico desplegado (2008). $Y$ este no es necesariamente inferior al de los técnicos que trabajan en las divisiones del Estado.

La experticia ciudadana tiene particularidades que la hace distinta al saber técnico desplegado por y desde el Estado o del ámbito privado. Es propia de los usuarios o "afectados". En este sentido, el saber ciudadano que describimos aquí se acerca a la idea de contra-experticia que describen Ollitrault y Jouzel (2015), es decir "una práctica contestataria característica de los 'nuevos movimientos sociales' que están particularmente dotados de capitales culturales y sociales" (Ollitrault y Jouzel 2015: 86).

Por otra parte, en la construcción de la contraexperticia, si bien los ciudadanos pueden 
ser críticos, también ocupan los saberes institucionales: los ciudadanos descubren y reivindican reglamentos o leyes olvidadas, algunas veces desconocidas por los propios funcionarios o políticos.

El saber ciudadano cumple un rol fiscalizador algunas veces, como el de destapar irregularidades, pero también otras veces es solicitado por las instituciones públicas y privadas (Ollitrault y Jouzel 2015), que esperan que los ciudadanos cumplan su rol contestatario creando un conocimiento e indicadores diferentes. Si bien esto aún no es recurrente en Chile, o en muchas ocasiones no está normado, los funcionarios necesitan del rol crítico o fiscalizador de la contra-experticia por diversos motivos. Uno de ellos es que concretamente los funcionarios están sobrepasados y no logran cumplir el rol fiscalizar en los territorios en cuestión. Otro, es que en los casos que estudiamos los miembros de las organizaciones civiles han adquirido mayores competencias y grados de especialización que los trabajadores del sector público. Además, la contraexperticia permite difundir y socializar un saber desconocido por la mayoría. Los funcionarios necesitan que más habitantes estén al tanto, por ejemplo, de los riesgos de vivir en una quebrada, como en el caso de Lo Cañas, lo que podría evitar futuros aluviones, inundaciones y los riesgos asociados.

Contrariamente a lo que señalan Ollitrault y Jouzel (ibid.), quienes ven una fuerte posibilidad de agotamiento y limitación de los actores comprometidos en movimientos sociales encargados de la difusión e institucionalización de la contra-experticia, en los casos aquí analizados ocurre lo contrario. El saber ciudadano experto les da, en algunos contextos, legitimidad (ibid.) pero además les permite tener un rol y un lugar en los debates y en la contestación de las políticas públicas y de los cambios, gestión y administración de los territorios. En este sentido, como los ciudadanos son raramente convocados a participar y dar su opinión, y sucede menos aún que ésta sea vinculante, el poseer un conocimiento experto, único, les otorga un lugar que no necesariamente está estructurado por los dispositivos de la democracia, sino que lo han forjado ellos mismos. A continuación, veremos tres formas o procesos a través de los cuáles logran ocupar este rol.

\subsection{Las organizaciones desde el trabajo de campo.}

La Red de Defensa de la Precordillera es una asociación ciudadana que busca proteger el que consideran el último bosque de la precordillera de Santiago. La etnografía fue llevada a cabo en cuatro etapas entre el 2007 y el 2010. En el 2007, durante el mes de noviembre, realizamos un terreno preliminar para tomar contacto con la asociación e investigadores trabajando sobre la cuestión de la precordillera. Luego, realizamos el primer trabajo de terreno de 8 meses (abril-noviembre). El segundo periodo de etnografía fue realizado entre octubre 2009 y marzo 2010. El tercero, de octubre a noviembre 2010. Posteriormente seguimos de lejos las actividades y conversaciones con la asociación por medio de correos y teléfono. En total, 59 entrevistas fueron realizadas, asistimos a 37 reuniones (internas de la asociación como con otras asociaciones, funcionarios, autoridades varias, profesionales e investigadores). $\mathrm{Y}$ participamos de 18 actividades diversas: manifestaciones, exposiciones, presentaciones, debates y seminarios públicos. 
En el caso de Vecinos por la defensa del barrio Yungay el trabajo de campo se realizó entre los años 2007 y 2011, tiempo en el cual realizamos entrevistas a los dirigentes reconocidos como la "cara visible" de la agrupación, analizamos el sitio web de la agrupación (359 entradas) y asistimos a una treintena de reuniones, a una veintena de actividades públicas desarrolladas por la agrupación en el barrio. Además, asistimos a reuniones administrativas y académicas donde los dirigentes de la agrupación asistían como expositores. Finalmente, analizamos la revista Bello Barrio que la agrupación publicó gracias a la obtención de fondos públicos.

Uno de los objetivos de los VDBY es la defensa de la "vida de barrio", frente a lo cual desarrollan una serie de actividades, entre las que destacan las orientadas al público en general, más o menos masivas, donde la idea era convocar a los vecinos y a otros visitantes del barrio para relatar la lucha que estaban realizando. El segundo tipo de actividades eran reuniones en instancias técnicas, académicas y políticas donde los dirigentes difundían su propuesta de defensa barrial y patrimonial. El despliegue en ambas instancias permite plantear que los principales dirigentes de esta agrupación son jóvenes profesionales universitarios con experiencia política, capaces de moverse en distintos ámbitos.

Cuando asistimos a las primeras reuniones de la organización RDP, nos encontramos con un pequeño grupo de ocho habitantes de los

\footnotetext{
La agrupación analizada se puede dividir en al menos tres grupos: el grupo central o cara visible conformada entre dos a cinco personas, luego un grupo de unas diez personas colaboradoras constantes, y luego a un número mayor que puede ascender a las cincuenta personas que se vinculan con la agrupación dependiendo de la naturaleza de la actividad que se organiza.
}

barrios "altos" (tanto geográficamente como socialmente) de la Florida. En este pequeño grupo, en que sólo cinco o seis personas asisten regularmente a las actividades, está compuesto casi mayoritariamente por mujeres cercanas alos sesenta años, profesionales (tecnóloga médica, traductora, artista, arquitecto, profesora son algunas de las profesiones del grupo fundador de la RDP), algunas ya jubiladas y otras por jubilarse o trabajando esporádicamente. Hay algunos jóvenes profesionales (abogado y arquitecto) y estudiantes universitarios (de derecho principalmente). Estos últimos se van a ir integrando progresivamente, más bien hacia el 2009. El grupo original es sin embargo poco heterogéneo: se trata de un grupo de amigas de clase media y alta que se encuentra, dos a cuatro veces al mes, en las tardes para discutir, prever acciones en el seno de la RDP. Sin embargo, poco a poco las actividades se masifican ${ }^{6}$.

Si bien no tenemos el espacio aquí para abordar el proceso de masificación y movilización del movimiento, cabe señalar que, en términos generales, el periodo en que realizamos la etnografía estuvo marcado por reuniones esporádicas que no tienen calendario fijo y tienen intensidad fluctuante. En ese entonces, la líder de la agrupación, principal contacto y puerta de entrada, abarca casi todas las tareas: organizar las reuniones, responder los correos, tomar contactos con otros actores relevantes, ir a la municipalidad para obtener información

En enero 2012 logran realizar un plebiscito consultativo, no vinculante, el cual es finalmente organizado por la Municipalidad de La Florida y fuertemente criticado por la asociación por la manera en que se planteó la pregunta: "Ud. Aprueba la decisión de la Municipalidad de defender el bosque El Panul y de modificar el Plan Regulador para proteger la precordillera de La Florida?". Finalmente, el $98 \%$ de los votos emitidos se pronunciaron en favor de la defensa del lugar. Sin embargo, tal como lo anunciaron los miembros de la RDP, este resultado no cambió en nada la suerte del Panul. 
y resolver dudas, escribir a las autoridades, etc. En este contexto, la RDP está prácticamente conducida solo por la líder, y fue así como surgió el desafío etnográfico de estudiar esta forma particular de acción colectiva: esa aparente apatía o falta de motivación en la movilización se fue transformando, gracias a la etnografía, en un análisis de las particularidades de una acción colectiva, caracterizada por micro-procesos cotidianos, que no sigue las formas clásicas de movilización como la movilización en la calle, ni actos masivos de protesta (Biskupovic 2017).

El objetivo de la RDP de defender la precordillera, evitar los condominios, proteger la vegetación endémica, puede parecer en un principio como un compromiso parecido a la ecología militante (Latour 2004 : 35 ; Thevenot y Lafaye 1993). Sin embargo, los miembros de la RDP no sólo están preocupados por la ecología sino también por las ciencias, la calidad de vida, la política y los modos de vida en la precordillera (Biskupovic 2017).

\section{El saber ciudadano a partir de tres dimensiones.}

En la búsqueda por el saber respecto al territorio y la controversia, los miembros de las organizaciones que aquí estudiamos, investigan el espacio en el que viven. En esta investigación seleccionan información, participantes, emociones, entre otros aspectos, los que producen discursos, reglas, mecanismos de poder específicos.

Comienza así lo que Bridge denomina una aproximación transaccional del espacio transactional space - donde más que definir el territorio como algo inequívoco, desde una certeza epistemológica o una racionalidad a priori, se lo define desde la solución de diferentes problemas y sus consecuencias en el mismo territorio, así como de la reunión de saber (Bridge 2013). El territorio así comienza a tener características y cualidades en relación a otros territorios, y a las contingencias a las que tenga que hacer frente.

Bridge (ibid.) postula la idea que el territorio se construye en una transacción, relación caracterizada como un proceso de ida y vuelta donde sentidos, afectos y emociones son parte constitutiva (ibid.). Así la construcción y definición del territorio serían producto de la relación entre individuos o colectivos con un espacio definido, sobre el cual los sentidos, afectos y emociones se involucran y relevan en el contexto de la resolución de problemas (ibid.).

Sin embargo, esto se enfrenta a lo que hemos señalado antes, que los agentes que administran - o intentan administrar - los territorios y barrios que aquí abordamos raramente incluyen a sus usuarios. El saber ciudadano que despliega organizaciones como las aquí estudiadas muchas veces se enfrentan a las políticas públicas, materializadas en proyectos y sus efectos que implican cambios en su diario vivir. Esto no debiese sorprendernos, el diseño de políticas públicas, en su definición primera, intenta canalizar o reglamentar, con resultados exitosos y fracasos, demandas y necesidades que emergen de la ciudadanía (ver Ureta 2017). Podríamos argumentar que nadie sabe mejor que estos ciudadanos o vecinos sobre las necesidades que tienen (retomando la idea de Dewey planteada más arriba), canalizados a través de asambleas, juntas de vecinos, asociaciones, entre otros. Los expertos no siempre son los profesionales o los científicos, estos pueden ocupar roles complementarios o 
consultivos en los casos aquí estudiados, en particular cuando los ciudadanos son los que convocan y levantan causas.

En esta misma línea, el ciudadano experto, tal como plantean Collins y Evans (2007), no es una condición que provenga de una acreditación necesariamente, sino que el experto es aquel que logra una experticia real y sustantiva en base a la participación de un grupo de expertos, así "la adquisición de experticia, es un proceso social un tema de socialización dentro de las prácticas de un grupo de expertos - y que dicha experticia puede perderse mientras más tiempo se esté lejos de este grupo" (Collins y Evans 2007: 3).

El saber es construido en el marco de la vida asociativa y si bien dialoga con la política institucional (partidos políticos, movilizaciones sociales, participación en las elecciones y votaciones, desafección política), es indisociable de la experiencia cotidiana de la vida pública de estos barrios y asociaciones. Esta experiencia está ligada a dificultades que atraviesan los ciudadanos para hacerse escuchar e influir en las decisiones concernientes a sus barrios, centralmente en dos escalas: una barrial, es decir, los desafíos de los habitantes en la convivencia política para lograr objetivos, ya sean estos conmemorar una fecha, organizar un picnic, concertar una reunión con un concejal, o simplemente reunirse a conversar sobre un tema de interés; también a escala metropolitana: como estos ciudadanos se transforman en participantes, interactuando y haciéndose escuchar o no en las instancias de toma de decisión a nivel metropolitano.

La incapacidad de integrar el saber de los usuarios en los cambios y controversias barriales por parte de los expertos, técnicos o agentes del Estado está poco o nulamente formalizada, institucionalizada. Sin embargo, frente a esta falta de incorporación del conocimiento de los ciudadanos, ya sea por indiferencia, dificultades, trabas, los ciudadanos crean una manera propia de participar, de entrar en política (que no tiene que ver directamente con partidos políticos), crean una comunidad política donde discuten del territorio, despliegan saberes y actúan como traductores del conocimiento experto.

Siguiendo estas constataciones, analizaremos el saber ciudadano a partir de tres dimensiones. Primero, en tanto que permite crear una forma política donde a su vez se construye un proyecto político propio. Segundo, el saber ciudadano crea una comunidad política donde se discute y construyeel territorio. Tercero, el saber ciudadano transforma a los habitantes comprometidos en traductores del conocimiento experto y si bien no siempre les asegura reconocimiento y legitimación por parte de las autoridades, les permite ocupar un rol en la democracia.

\subsection{El saber en la creación de un proyecto político propio?.}

Tanto el proyecto político de la Red de defensa de la precordillera como el de los vecinos por la defensa del Barrio Yungay no se define siguiendo estrategias preestablecidas. La política se vuelve un proyecto constantemente en debate, construido, puesto en cuestión, imaginado y reformulado por sus miembros. En este marco, la adquisición de un saber es necesaria tanto en el proceso de transformarse en ciudadano

Los principales hallazgos aquí presentados han sido extraídos de la tesis doctoral de la co-autora de este artículo, Consuelo Biskupovic, la que se tituló "Forjar la participación: una etnografía de la cultura cívica experta en Santiago, Chile" (EHESS, París y Universidad de Chile). 
comprometido, defensor del barrio y territorio, como para interactuar colectivamente en el seno de la asociación y participar en las arenas públicas de debate.

Los miembros de los colectivos estudiados, en el proceso de aprendizaje y de intento de resolución de las controversias, definen objetivos a alcanzar, participando de una vida colectiva y en la esfera pública. En este sentido, el saber experto ciudadano es indisociable de las interacciones, de la vida colectiva de la asociación (Biskupovic 2015).

Respecto a la RDP, cabe señalar que, en el transcurso de la configuración y definición del proyecto político, las controversias en torno a la protección delafloray fauna de la precordillerahan jugado un papel central en la formación del saber ciudadano sobre la precordillera en específico. Es decir que, frente a la indeterminación, los ciudadanos se movilizan. Por eso es que se considera que "(l)as controversias constituyen un enriquecimiento de la democracia" pues su desarrollo favorece nuevos conocimientos y aprendizajes (Callon et al. 2001: 49). El desarrollo de una experticia en relación al riesgo de aluviones ligado a vivir en zonas precordilleranas, tal como ocurrió en el año $1993^{8}$ para enfrentar los efectos del desarrollo de nuevos proyectos inmobiliarios generalmente son percibidos con indiferencia por las autoridades públicas puesto que obstruyen o retardan los proyectos (Callon et al. 2001). Sin embargo, la indeterminación y la incertidumbre generan procesos de adquisición

El aluvión en la Quebrada de Macul, uno de los peores desastres en Chile, según una nota de prensa, ocurrió en mayo de 1993 dejando 26 muertos, 8 desaparecidos, 32654 afectados y 307 viviendas destruidas (El Mercurio 2009). Para la época, fue considerado uno de los aluviones más grandes ocurrido en Santiago, afectando a cinco comunas y a cerca de treinta mil personas (Secretaría Regional Ministerial de Salud, 1999). de un saber específico por parte de los vecinos, afectados por los riesgos. Las controversias en torno a la precordillera, cómo definirla, cómo debiera ser habitada, cuáles son sus límites, a quién pertenece, son "potentes dispositivos de exploración y aprendizaje de mundos posibles" (Callon et al. 2001: 50).

El aluvión de 1993, los cambios en el uso de suelo, las modificaciones en la gestión del territorio son hechos sociales que transforman los saberes disponibles. Los eventos "naturales" y el proyecto político de la asociación los impulsa a desarrollar el saber, puesto que aparecen nuevos desafíos, nuevos procedimientos que cuadrar y comprender.

¿Pero a qué les da acceso el saber ciudadano experto a los miembros de la RDP? Tener competencias científicas (ecológicas, geográficas, geológicas, etc.) y técnicas (conocer las leyes, los medios de participación, los procedimientos legales, etc.) les permite acceder a las arenas políticas de discusión, ya sea en el seno del Municipio de La Florida, en la Intendencia u otros organismos públicos, pero también discutir con abogados, arquitectos, geógrafos y autoridades.

Los líderes de la RDP deben hablar el "mismo idioma" de los funcionarios o investigadores para comunicarse. Esta lengua corporal, escrita y oral se aprende y supone un uso conocido por quienes pertenecen al grupo.

El riesgo no siempre se puede medir, explica L. ${ }^{9}$, miembro de la RDP desde sus inicios. La naturaleza, la precordillera, no se puede

\footnotetext{
L. tiene sesenta años en el momento de la investigación, jubilada de la Universidad de Chile (trabajó en el departamento de Ingeniería como asistente en rayos X), vive en Lo Cañas.
} 
estabilizar ni controlar. Sólo el saber permite conocer su comportamiento y eventualmente anticipar para evitar nuevos desastres, para disminuir la incertidumbre. Los miembros de la RDP investigan, definen problemas y difunden soluciones con la esperanza que estas sean escuchadas por las autoridades. Estas definiciones son el resultado de un largo proceso de intercambio de saberes entre vecinos, autoridades, expertos.

En el transcurso de la etnografía que realizamos entre el 2007 y el 2010 con los miembros de la Red de defensa de la precordillera, pudimos constatar que las reuniones con funcionarios municipales, autoridades metropolitanas o profesionales y académicos son una suerte de "escuela" para los miembros del colectivo. Gracias a las interacciones entre los actores, las reuniones se transforman en "una escuela para los ciudadanos en el seno de la democracia" (Biskupovic 2015: 227) en el sentido en que, en éstas, los ciudadanos tienen acceso a nuevas informaciones, modificaciones relativas a los planos reguladores, por ejemplo, u otras reglamentaciones relativas a la planificación urbana. Además, los miembros van adquiriendo mayor experiencia tanto técnica como política, las que van permitiéndoles adaptarse mejor a las interacciones, construir estrategias políticas y comprender lo que sucede. Para que sus demandas sean escuchadas, deben además de entender qué pasa, comprender y estudiar la factibilidad de éstas. Es a través de estos espacios efímeros de intercambios entre ciudadanos, autoridades y expertos que se pone en práctica la participación ciudadana concretamente, en tanto que acción cotidiana forjada por los ciudadanos.

En sí, el saber se adquiere gracias a las acciones cotidianas de los miembros del colectivo, a las actividades que desarrollan en el barrio, en la precordillera, pero también gracias al entorno social.

Los espacios como las reuniones y los encuentros entre ciudadanos y funcionarios o profesionales muestran que los colectivos estudiados "participan de la renovación de la vida cívica en Chile" (Biskupovic 2015: 183). Los ciudadanos se forman, aprenden y desarrollan un saber propio gracias a los intercambios que ellos mismos crean, solicitando reuniones con diferentes actores claves para plantearles sus demandas.

El saber que desarrollan cambia las relaciones entre los habitantes y la ciudad, entendida como un conjunto amplio de barrios, medio ambientes, espacios, construcción, interacciones sociales entre humanos y no-humanos. En la medida que los miembros de la RDP difunden y traducen informaciones respecto a los territorios, van instalando problemas o controversias en la escena pública, en medios locales, en juntas de vecinos, o entre los mismos vecinos. Aun cuando la mayoría de las veces los problemas planteados por los colectivos son negados por las municipalidades, los vecinos movilizados crean nuevos espacios de debate y arenas públicas de discusión (Gusfield 1981; Cefaï 1996).

La actividad política de los colectivos son instancias de aprendizaje, momentos en que los ciudadanos participan en la "escuela de la democracia" y a la que no podrían acceder sin una destreza y un saber adquirido. En este sentido, la vida asociativa requiere un trabajo de los ciudadanos que implique un compromiso continuo (Hamidi, 2010) y una preparación constante. 
Tal como señala Saurugger, la experticia es "profundamente política" (2002: 375). En los casos estudiados, la RDP y los VDBY son ellos mismos quienes crean las instancias de participación. Para ello, requieren de una preparación y la construcción de un saber que se actualiza. Parte del proyecto político y de la vida asociativa de estas organizaciones consiste en desarrollar este saber propio respecto al territorio. Además, gracias a la experticia, los miembros de estas organizaciones sienten que sus demandas son justas (Nardacchione 2011) y justificadas.

Los miembros de estas organizaciones se vuelven interlocutores en el seno de la democracia, el saber que desarrollan les da un lugar y un rol en la discusión sobre el Panul, sobre la precordillera, sobre el Barrio Yungay y el patrimonio. Además, al buscar el saber, los ciudadanos encuentran entre los profesionales (abogados, científicos, miembros de ONG), que son en gran medida los productores del saber que ellos buscan, representantes legítimos. Estos representantes no sólo pueden hablar en el nombre de las causas defendidas, sino también hacen circular las demandas de los ciudadanos en el corazón de las instituciones y en otras arenas (medios de comunicación, libros, artículos, congresos, seminarios, etc.). Estos representantes, además, van a "certificar" los argumentos de los vecinos, se transforman en los "garantes" de las causas defendidas.

El saber es parte del proyecto político RDP y VDBY. Estos proyectos, la creación, continuidad y difusión de éstos, son indisociables de un saber que es construido, almacenado, desclasificado y difundido por los ciudadanos. El saber es el que "hace vivir" la organización, la defensa del territorio; la legitima frente a ciertos públicos y permite a los vecinos "enfrentarse" con las autoridades.

\subsection{La discusión y construcción del territorio como el saber ciudadano de una comunidad política.}

Los Vecinos por la defensa del Barrio Yungay nacieron hace 14 años en un conflicto con el Municipio de Santiago sobre el régimen de retiro de la basura. Desde ese momento en adelante han hecho frente a diferentes proyectos en el barrio, tanto del Municipio como de agentes privados, que para ellos significan la interrupción o puesta en riesgo de elementos importantes del barrio, ya sea porque modifican significativamente la rutina del barrio o porque van en contra de la historia e identidad de éste.

Es importante aclarar que los VDBY no se oponen intrínsecamente a los cambios, sino que más bien a aquellos que 'atentan' contra el barrio deseado por los vecinos de esta agrupación. Pero la definición del barrio o del barrio deseado no fue establecida a priori, sino que nació al alero de diferentes disputas, las cuales fueron enmarcando y enriqueciendo la definición del barrio.

Para la elaboración de la definición del barrio que defienden los VDBY, dicha agrupación ha enfrentado diferentes problemas. En primer lugar, ha tenido que construir un saber sobre el barrio que dialoga/entra en conflicto con otros saberes, en segundo lugar, han tenido que elaborar un relato identitario del barrio y en tercer lugar ha tenido que darle una continuidad con otros espacios que contiene y que lo contienen.

En relación al saber sobre el barrio, no es que con anterioridad a la organización este conocimiento no existiese, sino que este descansaba de manera implícita en la rutina del barrio, es decir, que en muchos aspectos no estaban 
explicitados, sino que más bien es un factor tácito en la relación de los vecinos del barrio. Es el paso que Collins (2010) plantea entre el conocimiento tácito y el conocimiento explícito, donde este último permite ser comunicado a otros, en este caso, a otros que no conocen o no habitan en el barrio.

Para el saber sobre del barrio, la agrupación plantea que "hay que construirlo, [pues] el discurso es más oral, el que tenemos nosotros...". (Dirigente $1^{10}$ de VDBY). Por ejemplo, las rutas que hay que seguir para evitar los peligros del barrio, o qué y cómo comprar en los almacenes del barrio son consejos y saberes muchas veces "encerrados", puertas adentro. Son estos saberes justamente los que hay que "elaborar" para que sean posibles de comunicar a terceros. Tienen que salir del espacio doméstico para ser compartidos como una forma de entender y vivir el barrio.

El saber sobre el barrio, basado en la vida rutinaria, busca resolver problemas cotidianos de los vecinos. En este sentido, las preocupaciones son "la calidad de vida, la basura, el tema de las torres, después cuando entramos al tema de la zona típica, que....bueno, que no quieren que le destruyan sus casas, si tienen hijos, etcétera... un departamento de dos por dos, cuando tienen una casa de cien metros cuadrados, y ahí además viven dos o tres familias, la abuela... en general a la vida cotidiana, y es eso lo que les da el respaldo... le estás hablando de los mismos códigos comunitarios, de los mismos códigos de su vida cotidiana..." (Dirigente 1 de los VDBY).

Joven profesional universitario que habita en el barrio y tiene un rol protagónico en la agruación.
De esta forma el territorio, en este caso el barrio $^{11}$, va tomando la forma de la enunciación y solución a los problemas cotidianos de sus habitantes. El barrio se comienza a construir en la medida de las necesidades de quienes viven ahí, y el desarrollo futuro del barrio es delineado en torno a las proyecciones de los vecinos, lo que no necesariamente coincide con los proyectos de agentes inmobiliarios o del Municipio.

Esta no coincidencia o discrepancias entre lo que los vecinos definen como el futuro deseable del barrio y lo que agentes públicos o privados proponen para el mismo, forman parte importante en la definición del barrio. De esta forma, no es solo el saber cotidiano el que configura el territorio, sino que éste en interacción y conflicto con otros saberes e intenciones frente al territorio.

De esta forma, el barrio no es una creación a priori, sino que más bien se construye en la resolución de problemas, y en un dialogo (algunas veces conflicto) con otros actores relevantes en y para el territorio en cuestión.

En segundo lugar, los VDBY no solo han relevado el conocimiento de la vida cotidiana del barrio, sino que también intentan mostrar el conocimiento histórico del territorio, mostrado cómo el barrio es un lugar destacado en la ciudad.

En una de las primeras 'entradas' su sitio web, la agrupación destacaba que el barrio Yungay

En este artículo no desarrollaremos la discusión epistemológica entre espacio y territorio o espacio y lugar, sino que más bien nos basaremos en la idea de espacio transaccional desarrollada por Bridge, planteando que el barrio es el espacio producto de la transacción que realizan los vecinos. 
no es "cualquier barrio", si no que se trata del "primer barrio de Santiago" que ha dado cuenta a través de los años de los cambios no sólo de la capital, sino que de la sociedad chilena en general. Ha visto llegar y ha albergado emigrantes de afuera y de dentro del país, ha sido habitado por diversas clases sociales, cuna de organizaciones y agrupaciones de diferente índole y ha servido de inspiración a creadores del ámbito artístico, patrimonial y urbanístico. ${ }^{12}$

Finalmente, el tercer problema a resolver por la agrupación ha sido situar el barrio en conexión con otros espacios. La agrupación lo ha resuelto mediante una operación escalar donde el barrio es descrito a partir de espacios en su interior, pero también, la definición del barrio ha sido desarrollada desde su relación con escalas mayores.

Hacia dentro del barrio, la agrupación realza la presencia de plaza y calles, aceras y fachadas. Pequeños espacios que a juicio de la agrupación dan contenido al barrio. Pero esos espacios no tendrían la centralidad que tienen si no fuera por quien los habita: el vecino.

El vecino es aquel que habita el barrio, el que utiliza las aceras y compra en el comercio local, y se constituye entonces en el centro de la defensa, pero también en el proyecto político hacia la ciudad. Es su ritmo el que está al centro de la defensa.

Ahora, hacia el exterior del barrio, este se comienza a entender sólo en conexión con escalas mayores. "Para mí no es un cambio, para mí es que la organización ha tenido la

Información extraída del sitio web www.elsitiodeyungay.cl, consultado en marzo de 2018. capacidad de trabajar a tres niveles: el nivel local, territorial de Yungay, el nivel ya del tema patrimonial pero a nivel nacional, y ahora también en una plataforma mucha más amplia encontrarse con otros movimientos ciudadanos y sociales parecidos a los nuestros, pero que están en otros temas [...]" (Dirigente 2 de los VDBY $\left.{ }^{13}\right)$.

De esta forma, el barrio se comienza a entender por un lado desde el vecino, una suerte de piedra angular al centro de la defensa y del proyecto del barrio, que es justamente quien habita el barrio. Pero a su vez, el barrio se entiende como parte de una continuidad con el resto de la ciudad, con el resto del país e incluso de otros temas que van más allá de formas de habitar la ciudad.

En síntesis, podemos plantear que el saber de la agrupación puede crear lo defendido, en este caso el barrio, no en el entendido de construir una entelequia, sino que más bien de configurarlo tanto desde el conocimiento sobre el barrio, el realce del barrio en la ciudad y finalmente, su ligazón interna y externa con otras escalas.

La reunión de todos estos elementos reviste a la agrupación de defensa o a los habitantes del barrio como un actor imprescindible en las discusiones sobre el devenir del territorio.

\subsection{El rol del saber ciudadano en las transacciones sociales.}

Los ciudadanos, teniendo a su disposición un conjunto de competencias técnicas, que ellos mismos se han encargado de construir

Joven profesional que ha habitado toda la vida en el barrio y que dirige la agrupación. 
(recopilando, juntando, leyendo, descargando) exponen este saber para lograr que se acepte la defensa de la precordillera o del barrio Yungay. Sin embargo, el saber ciudadano no siempre les permite un reconocimiento o legitimidad inmediata. Tal como veremos, la legitimidad del saber está dada por el público en términos de a cuántos puede representar el saber. $O$, dicho de otro modo, el saber debe representar a una mayoría para considerarse democráticoy portanto legítimo. En el caso de la precordillera, el saber desplegado por los ciudadanos no convence a la audiencia, pues los funcionarios con quienes discuten consideran que la argumentación con la que quieren proteger la precordillera representa únicamente a quienes pertenecen a la agrupación. Por ende, el desafío para encontrar legitimidad y representatividad con el saber es lograr que éste represente a un grupo mayor, desde el punto de vista de las autoridades.

El acceso al saber, y sobre todo su actualización constante, exige a los ciudadanos no sólo mantenerse al tanto, sino que reactualizar sus saberes y renovar las pruebas cuando estas no son aceptables para las autoridades. Por ejemplo, en muchos casos los ciudadanos citan trabajos universitarios y académicos, es decir, científicos, con el fin de respaldar sus convicciones. Tienen, además, deberes morales hacia las autoridades que los reciben. Los encuentros y las interacciones entre ciudadanos y autoridades no se dan siempre en marcos institucionales, no siguen necesariamente dispositivos de participación regulada, institucionalmente. Se trata de solicitudes informales que hacen los vecinos encargados de defender el barrio y la naturaleza, donde se muestra no sólo la experticia, sino también expectativas morales, afectivas, sentimentales.
Por ello, el saber ciudadano no sólo implica el trabajo cotidiano de desclasificar decretos, por ejemplo, que permitan proteger el patrimonio de un barrio o un bosque, o divulgar información científica que fortifique los argumentos para defender un lugar.

En el caso del Barrio Yungay, esta desclasificación se puede ver en el despliegue de argumentos de los VDBY en su sitio web. Las primeras entradas dando cuenta de la historia del barrio, sorpresa frente a nuevas edificaciones o molestia frente al cambio del regimen de retiro de la basura comienzan a ser reemplazadas por los esfuerzos ciudadanos por levantar instancias donde los vecinos puedan comenzar a hablar en el lenguaje técnico del Municipio. Así nacen los Cabildos del barrio, donde en diferentes comisiones, los vecinos discutirán y propondrán ideas para el desarrollo del barrio.

Por otro lado, cuando una agrupación ciudadana se esfuerza para que su barrio cuente con la denominación de barrio patrimonial, debe entrar en el lenguaje técnico administrativo elaborando un "informe técnico" para lo cual se ponen en contacto con diferentes vecinos que manejen el lenguaje técnico administrativo $y$, por otro lado, toman contacto con Universidades en busca de ser apoyados en la elaboración de sus argumentos.

Ambas agrupaciones cuentan entre sus miembros 0 adherentes a estudiantes 0 profesores universitarios, quienes muchas veces vinculan a las casas de estudio con las acciones que realiza la agrupación en el barrio. Dada esta relación, la agrupación acoge a estudiantes en práctica o en el desarrollo de sus tesis de grado (pre y post), así como los dirigentes de la agrupación asisten de manera 
regular a exponer en diferentes actividades pedagógicas $\mathrm{o}$ a exponer en seminarios 0 encuentros académicos.

El saber ciudadano es también saber manejar transacciones sociales compuestas por exigencias morales y exigencias de justicia (Blondeau y Sevin, 2004; Boltanski 1990; Boltanski 2007). Es decir, es saber también hacerse un lugar en la democracia.

Desde el 2010, las modificaciones al Plan Regulador Metropolitano (PRMS) se discutían en la Intendencia de Santiago. En el contexto de nuestra etnografía con la RDP, estuvimos presentes mientras estas modificaciones eran examinadas por las autoridades encargadas de votar, bajo los ojos atentos de los ciudadanos, presentes, pero sin poder votar. En términos generales, varias organizaciones junto a la RDP y otras como Defendamos la Ciudad ${ }^{14}$ habían manifestado su oposición a las modificaciones presentadas por el Ministerio de Vivienda y Urbanismo. Para resumir, los ciudadanos ponían en cuestión, sobre todo, la extensión del límite actual de Santiago.

El 5 de noviembre del 2010, la RDP asiste a la Intendencia para participar de una discusión entre autoridades y representantes de la sociedad civil respecto al tema de las modificaciones al PRMS. Además de los miembros de la RDP, un miembro de Defendamos la Ciudad, otro representante de la comuna de La Pintana y los trece consejeros

14 Esta organización nace a fines del año 1997 y está básicamente constituida activamente por dos miembros. Su presidente publica continuamente artículos de prensa para dar a conocer y denunciar irregularidades en relación a conflictos y nuevos proyectos urbanos. Disponible en: http://www.defendamoslaciudad.cl/ index.php/organizacion, consultado en marzo de 2018. regionales de la Comisión rural del Gobierno Regional de Santiago (GORE), representando a diferentes partidos políticos, están presenten en la reunión. Los representantes de la sociedad civil manifiestan su preocupación frente a la "incorporación de una superficie de 9545 hectáreas a la zona metropolitana de extensión urbana", como lo anuncia un consejero regional al comienzo de la reunión. Sin embargo, los funcionarios reaccionan con indiferencia frente a las preocupaciones y problemas que revelan los ciudadanos presentes, aun cuando estos últimos insisten en "hacerse escuchar" entre las autoridades. Si bien los ciudadanos despliegan saberes, tienen dificultades en ser reconocidos como interlocutores por las autoridades y funcionarios públicos.

A pesar de la tensión que se desencadena en estos encuentros, existe una reciprocidad en las interacciones, en ciertos momentos, los ciudadanos informan a las autoridades a quiénes les cuesta comprender el problema de la precordillera, por ejemplo. En otros momentos, son los ciudadanos quienes aprenden de las autoridades. Circulan saberes, emociones y expectativas.

Al comienzo de la reunión, el Presidente de la comisión (miembro del Partido Socialista) indica que han intentado procurarse la mayor cantidad de información posible respecto a las temáticas que levantan los ciudadanos presentes (precordillera, cambios en la ciudad). Sin embargo, uno de los consejeros que llega atrasado, irrumpe la modesta intención de cordialidad mostrada por el Presidente, criticando la presencia de los ciudadanos e intentando evitar que la discusión se centre en los temas que abordan los miembros de la RDP: 
Hay que ver alguna forma de abrir una discusión de más largo aliento que no tenga que ver solamente con las demandas que la ciudadanía tenga respecto de situaciones coyunturales.

Esta crítica al supuesto "egoísmo" de las demandas ciudadanas se expresa en teorías como las NIMBY (Not In My Back Yard) ${ }^{15}$. Sin embargo, en la construcción de un saber ciudadano se plasma el esfuerzo por intentar que las demandas tengan importancia "universal" o general. La defensa de la precordillera y del barrio es llevada hacia valores universales por los vecinos. Estos recalcan la especificidad y la importancia de la precordillera o del barrio, llamando a la preservación de la flora y fauna, y del patrimonio, lo que sería determinante para el contexto nacional y hasta planetario (sobre todo respecto a la protección de la naturaleza). Sin embargo, para desplazar los "particularismos" de los que son acusados, los vecinos necesitan ciudadanos legítimos que puedan llevar sus reivindicaciones hacia valores de importancia más general. Que puedan, así mismo, posicionar los lugares que defienden según un estatuto único en su género. Los miembros de la RDP no son considerandos ciudadanos legítimos en esta reunión con la Comisión rural, es decir, el público presente o la contraparte no considera que el saber desplegado representa a la mayoría, y en sentido que es "democrático". De manera implícita, uno de los consejeros presente considera que los ciudadanos no actúan, sino para su propio beneficio, minimizando el valor de la precordillera que los vecinos han venido a defender. Las autoridades no se sienten cómodas discutiendo de igual a igual con los

\footnotetext{
Según Jacques Lolive, este concepto, que evoca el egoísmo de los movimientos que se declaran opuestos a ciertos proyectos locales, estigmatiza los movimientos sociales y las asociaciones locales ya que sugiere que estos no tendrían otro objetivo más que desplazar los nuevos proyectos para que se instalen lejos de sus territorios (1997).
}

ciudadanos e intentan mostrarles no sólo sus posiciones de poder, sino que es "excepcional" que los reciban. El presidente de la comisión señala
No tenemos participación ciudadana, es muy poca la participación ciudadana y ustedes saben que en una sociedad como esta se impone la fuerza económica con respecto a algunas situaciones y en ese marco yo creo que los consejeros regionales en forma universal todos, de todos los partidos políticos que están aquí, están por interactuar con ustedes, relacionarse con el territorio porque ellos son elegidos por los concejales, los consejeros regionales son elegidos porque tienen una relación con la comuna, por lo tanto trátenlos bien a los consejeros regionales, más allá de que discutamos, que tengamos situaciones distintas, pero trátenlos bien porque es el único lugar, que yo estoy convencido, donde podemos interactuar con la sociedad civil organizada, ¿ya?.

La recomendación de cordialidad dirigida hacia los ciudadanos va de la mano con el lugar que les otorgan. Siguiendo a Mauss, podríamos ver en el lugar otorgado a los ciudadanos un "don" que obliga ser devuelto: agradecer y reconocer a las autoridades. Se trata, tal como sugiere Cefaï, de "transacciones sociales" donde lo que está en juego no son objetos sino "prestaciones, informaciones y satisfacciones" (Cefaï 2006: 38) que circulan de manera desigual.

Los ciudadanos saben que no obtendrán resultados concretos después de estas reuniones. Estos encuentros son para ellos el medio para hacer valer un conjunto de argumentos que justifican, según ellos, sus luchas. Las autoridades por su parte argumentan que ellos no pueden hacer nada, pero no lo justifican con argumentos legales, sino que recurriendo a un desinterés y una buena voluntad: "Porque lo hacemos pendientes porque no hay ningún interés (...), solamente la humanidad que tiene cada uno de nosotros para responder hacia la ciudadanía". 
Es difícil para los vecinos hacer valer el saber ciudadano construido a lo largo de los años, este pareciera tener poca importancia en estas interacciones e transacciones sociales. Las autoridades, en este caso, están lejos de disponer de una real experticia en relación a las regulaciones de la ciudad y la naturaleza. El presidente afirma que no los puede ayudar con las modificaciones al PRMS «porque nosotros tampoco lo conocíamos globalmente». Y más adelante, mientras los ciudadanos exponen argumentos científicos, algunos consejeros les preguntan si pueden enviar estas informaciones por escrito. Reciben poca atención, pero siguen exponiendo. Ambas partes asumen un cierto respeto y cordialidad para que los intercambios continúen y funcionen, a pesar de los desacuerdos y que no se escuchen. Estos intercambios son necesarios para ambas partes, de distinta manera según las circunstancias. El acceso a la Intendencia es difícil y más aún poder sentarse junto a comisiones y autoridades políticas. En cambio, en las municipalidades, los vecinos son conocidos y pueden mostrarse más provocativos o desafiantes.

A medida que aprenden el lenguaje experto y comienzan a expresarlo y a poder poner en marcha sus conocimientos específicos respecto a la cordillera o el barrio, los vecinos van tomando confianza y van solicitando cada vez más encuentros como estos. Si bien el saber en sí no les abre puertas específicas respecto a las autoridades, sí les permite ocupar y mantener un lugar y poder reaccionar frente a las decisiones de las autoridades en relación al territorio. En esos espacios efímeros de intercambios pasan a formar parte de las transacciones, responden a las autoridades y plantean el problema de la precordillera y el barrio Yungay frente a diferentes instituciones, más allá de la ausencia de los dispositivos de participación.

\section{Conclusión}

Nuestra reflexión respecto al saber ciudadano parte de la constatación que éste ha tenido poco espacio en la literatura de las ciencias sociales. Es decir, el saber se ha entendido mayoritariamente, o bien desde una perspectiva local ("conocimiento local"), o bien, desde el punto de vista de los expertos. Pero pocas veces se analiza el saber de los ciudadanos en tanto que saber experto. En este artículo buscamos incorporar al análisis de la acción colectiva, la participación y la defensa de territorios el saber que tiene la ciudadanía comprometida y movilizada, saber que muchas veces sobre pasa los conocimientos de funcionarios $y$ autoridades.

Vimos que los vecinos tienen saberes acabados y desarrollados, que además se ocupan de trasladar esos saberes entre distintas arenas (desde el mundo científico hacia las autoridades, por ejemplo) y que, además, estos saberes están fundados en evidencias científicas, legales y la experiencia directa por uso.

En la reflexión sobre procesos democráticos y participación, al pensar el rol otorgado a la ciudadanía desde la perspectiva del saber ciudadano planteada en este trabajo, se abren nuevas orientaciones. Una de ellas, es que la participación de la ciudadanía, impulsada, dirigida y enmarcada por el Estado, pudiese incluir y dar un rol preponderante a los saberes de los vecinos respecto a decisiones relativas a políticas públicas. La inclusión de estos saberes - que son más que únicamente promotores de 
movilizaciones y opositores a proyectos - puede a largo plazo evitar conflictos desencadenados por la falta de inclusión de la ciudadanía.

Otra es pensar la participación como un procedimiento constantemente en construcción, como una ciudadanía que se va configurando a la medida de los conflictos que esta misma enarbola. Para asegurar la participación de los vecinos, es necesaria una flexibilidad respecto a categorías y nociones tal como lo que es el barrio, sus límites y sus proyecciones. La participación no puede ser únicamente "observar" (señalar observaciones respecto a proyectos de desarrollo), sino que también puede y debiera ser propositiva. Es decir, que a partir del saber ciudadano se puedan adaptar proyectos, discutir normativa, crear reglamentaciones, pensar el desarrollo de los territorios, etc.

Contrariamente a esta idea, las políticas públicas consideran al vecino y a las organizaciones locales como entidades "por formar", es decir, los esfuerzos del Estado apuntan a capacitar a la ciudadanía en el conocimiento experto. Rara vez consideran que los vecinos puedan tener un saber válido y legítimo sobre los territorios en cuestión.

En este sentido la ciudadanía necesita el reconocimiento de su saber, el cual se encauza desde mecanismos establecidos y/o desde la apertura de nuevas formas de negociación con el aparato público.
El saber es un pilar fundamental en la construcción de la ciudadanía, ya que es en el desarrollo del saber ciudadano - a través de su experticia, desarrollo de contra-experticia y procesos de exploración - que la comunidad busca ponerse al centro en los procesos de decisión.

Desde las escuelas de democracia, las agrupaciones aquí analizadas configuran su entrada a la discusión pública y política, no sólo utilizando los canales preestablecidos, sino que creando nuevos caminos y nuevas arenas públicas. Para esto utilizan su saber, así como diferentes estrategias para hacerse del saber técnico, el que al mismo tiempo muchas veces los ha marginalizado cuando es utilizado por estudios técnicos (por ejemplo, estudios de impacto ambiental según la legislación chilena).

Desde el saber, las agrupaciones crean lo defendido, configuran lo que es el Barrio Yungay, por ejemplo, o el proyecto político de la asociación, creando espacios de participación para hacerse escuchar por autoridades. El saber configura lo defendido, enmarcando también la discusión.

Finalmente, ya sea en sus esfuerzos de traducción del conocimiento técnico para la organización o para los vecinos que representan o en la configuración moral de los espacios de discusión, las agrupaciones van creando espacios de discusión, y demarcando las medidas del saber técnico y de las obligaciones sociales y morales de los intercambios sociales. 


\section{Bibliografía}

Auyero, J. (2004). "¿Por qué grita esta gente? Los medios y los significados de la protesta popular en la argentina de hoy", América Latina Hoy 36: 161-185.

Barbier, M., Cauchard, L., Joly, P., Paradeise, C. \& Vinck, D. (2013). "Hacia un enfoque pragmático, ecológico y político de la experticia". Revue d'anthropologie des connaissances 7 (1): 1-24.

Barthe, Y. (2003). "De la décision à l'exploration: les transformations de l'expertise dans le domaine des déchets nucléaires". In Gilbert, C. (dir.). Risques collectifs et situations de crises. Apports de la recherche en sciences humaines et sociales. París, L'Harmattan. 129-143.

Berger, M. (2014). "La participation sans le discours". Revue électronique des sciences humaines et sociales.

Biskupovic, C. (2015). "Forger la participation. Une ethnographie de la culture civique experte à Santiago: le cas du Réseau de Défense de la précordillère", Tesis de doctorado. École des Hautes Etudes en Sciences Sociales, París y Universidad de Chile.

Biskupovic, C. (2017). "Expertise et amour dans la défense de la nature», SociologieS [En línea], Dossiers, L'expérience latinoaméricaine de la sociologie pragmatique francophone. URL: http://journals.openedition.org/sociologies/6255

Blok, A. y Jensen, T. (2011). Bruno Latour: Hybrid Thoughts in a Hybrid World. London, Routledge.

Blondeau, C., y J-C. Sevin. (2004). "Entretien avec Luc Boltanski, une sociologie toujours mise à l'épreuve". Ethnographiques.org 5.

Boltanski, L. (2007). La souffrance à distance. La présence des absents: Morale humanitaire, médias et politique. París: Gallimard.

---. (1990). L'amour et la justice comme compétences: trois essais de sociologie de l'action. París: Métailié.

Bridge, G. (2013) "A Transactional Perspective on Space", International Planning Studies, 18 (3-4): 304-320.

Callon, M. (2004). "The role of hybrid communities and sociotechnical arrangements in the participatory design". Journal of the Center for Information Studies. 5 (3): 3-10.

Callon, M., Lascoumes, P. y Barthe, Y. (2001). Agir dans un monde incertain. Essai sur la démocratie technique. París: Seuil.

Cefaï, D. (1996), "La construction des problèmes publics. Définitions de situations dans des arènes publiques". Réseaux 14 (75): 43-66.

Cefaï, D. (2006). "Une perspective pragmatiste sur l'enquête de terrain". La méthodologie qualitative, Armand Colin. 33-62.

Collins, H. \& Evans, R. (2007) Rethinking expertise. Chicago, Chicago: University of Chicago Press.

Collins, Harry (2010) Tacit \& Explicit knowledge. Chicago, Chicago, University of Chicago Press.

El Mercurio (2009). Las "lecciones" dejadas por los 16 peores desastres en Chile.

Estades, J., y Rémy, É. (2003). L'expertise en pratique. Les risques liés à la vache folle et aux rayonnements ionisants. Paris,
L'Harmattan.

Garretón, M., Joignant, A., Somma, N. y Campos, T. (2017). "Conflicto Social en Chile 2015- 2016: disputando mitos". Nota COES de Política Pública N4, julio. Santiago, Chile.

Gusfield, J. R. (1981). The culture of public problems: drinking driving and the symbolic order, The University of Chicago Press.

Hamidi, C. (2010). La société civile dans les cités: Engagement associatif et politisation dans des associations de quartier. Paris, Economica.

Isin, E. (2017) "Performative Citizenship" In The Oxford Handbook of Citizenship, ed. by Ayelet Shachar, Rainer Bauböck, Irene Bloemraad and Maarten Vink, 500-523. Oxford: Oxford University Press.

Landau, M. (2008). "Cuestión de ciudadanía, autoridad estatal y participación ciudadana”, Revista Mexicana de Sociología 70, num. 1: 7-45.

Latour, B. (2004). Politiques de la nature. Paris, La Découverte.

Ministerio Secretaría General de la Presidencia (1994). Ley $N^{\circ}$ 19.300, Ley Sobre Bases Generales del Medio Ambiente.

Lolive J. (1997). "La montée en généralité pour sortir du Nimby. La mobilisation associative contre le TGV Méditerranée". Politix 10 (39): 109-30.

---. J. (2006). "Des forums hybrides à l'esthétisation des espaces publics en France». Cahiers de géographie du Québec 50 (140): 151-171.

Mignolo, W. (2003). Historias locales / diseños globales: Colonialidad, conocimientos subalternos y pensamiento fronterizo. Sevilla, AKAL.

Nardacchione, G. (2011). "El conocimiento científico y el saber práctico en la sociología pragmática francesa. Reflexiones sobre la sociología de la ciencia de Bruno Latour y la sociología política de Luc Boltanski”. Apuntes de Investigación del CECYP 19: 82-171.

Nez, H. (2011). "Nature et légitimités des savoirs citoyens dans l'urbanisme participatif. Une enquête ethnographique à Paris". Sociologie 2 (4).

Ollitrault, S. y J-N. Jouzel (2015). "Contre-expertise", in Emmanuel Henry et al., Dictionnaire critique de l'expertise, Presses de Sciences Po, 86-91.

Saurugger, S. (2002). "L'expertise: un mode de participation des groupes d'intérêt au processus décisionnel communautaire". Revue française de science politique 52 (4): 375-401.

Secretaría Regional Ministerial de Salud (1999). Principales desastres: Región Metropolitana 1990-1999.

Sintomer, Y (2008). "Du savoir d'usage au métier de citoyen ?" Raisons politiques 3: 115-33.

Thévenot, L., \& Lafaye, C. (1993). Une justification écologique? Conflits dans l'aménagement de la nature. Revue Française de Sociologie, 34(4), 495-524.

Tironi, M. et al. (2011). "Organizaciones emergentes, 
participación ciudadana y planificación urbana: una propuesta de política pública". Camino al Bicentenario. Propuestas para Chile 2010, Universidad Católica de Chile: 275-305.

Ureta, S. (2017). Transantiago: o el fallido ensamblaje de una sociedad de clase mundial. Santiago: Universidad Alberto Hurtado.
Valderrama, L.B. (2014): La Historia de la Sismología en Chile a inicios del Siglo XX. Una mirada desde los actores. En: Valderrama, L. B. y B. Santander (coords.) Socializar conocimientos. Santiago, Redlnche Ediciones. 542-562.

Vecinos por la defensa del barrio Yungay, consultado el 24/03/2018 